\title{
Presentación
}

\section{Nuevas alfabetizaciones}

El término alfabetización fue entendido, en el marco de los sistemas educativos modernos y de sus prácticas pedagógicas hegemónicas, como la incorporación de las destrezas de la lectoescritura para tener acceso al mundo letrado y, de esta manera, conocer y participar en las principales prácticas sociales y culturales. Saber leer se circunscribía a un proceso de desciframiento de un código. Con posterioridad surgieron cuestionamientos y nuevas conceptualizaciones en torno a las prácticas de lectura y escritura, distinguiéndolas y complejizándolas. Hoy no sólo se desarrollan en el ámbito académico distintas perspectivas y líneas de investigación sobre estas prácticas, sino que se ha ampliado el significado de estar alfabetizado y se han pluralizado las alfabetizaciones posibles y necesarias. Ya no basta con un conjunto de destrezas genéricas, sino que se requiere de la pregunta acerca de los diferentes modos, sentidos y funciones de la lectura y de la escritura. Implica también acceso a nuevos códigos y formas de representación, entre las que se incluyen las nuevas Tecnologías de la Información y la Comunicación (TIC) y, por sobre todo, la capacidad de comprender los múltiples significados de las prácticas sociales y cul- turales actuales. En este sentido, los teóricos de la resistencia consideran relevantes las alfabetizaciones históricas, políticas y culturales.

Problematizando los nuevos sentidos dados a la alfabetización, hemos convocado a la presentación de nuevos artículos para la edición número 7 de esta revista. Aquí encontrarán, por un lado, un conjunto de trabajos circunscriptos al ámbito universitario dedicados a: la alfabetización profesional durante la carrera universitaria (Natale y Stagnaro); la inclusión de las TIC en el marco de procesos institucionales de innovación académica de una universidad pública (Ambrosino); la enseñanza de estrategias lingüísticas orientadas a la lectoescritura en el aula de Español como Lengua Extranjera y Disciplinar (Mattiolli y Demarchi); una experiencia de iniciación científica (Prósperi y otros); temas y problemas en torno a la noción de «escritura acadámica» (Falchini). En otro orden, y desde una complejización del concepto de alfabetización, se revisa el lugar que ocupan las mujeres escritoras en el canon escolar de los manuales de Literatura (Bórtoli).

En el marco de nuevas experiencias educativas, Caminos, Duarte y Lorenzoti dan a conocer un proyecto de radio escolar llevado a cabo en un 
barrio periférico de la ciudad de Santa Fe como un modo alternativo de enseñar lengua y literatura en una relación de transferencialidad con otras materias curriculares, en conexión con el barrio y con las prácticas de los adolescentes.

Temporetti nos permite analizar dos modelos para leer, pensar, narrar, adquirir y comunicar conocimientos que, si bien surgieron y se respaldaron desde distintos paradigmas, hoy conviven; y desde esa realidad aproxima algunas ideas para repensar la tarea de educar y enseñar y, en particular, los procesos de alfabetización en las primeras décadas del siglo XXI.

En los últimas dos secciones accedemos a una entrevista realizada por Perticará al Dr. José Manuel Pérez Tornero en la cual se interpela el concepto de alfabetización en el contexto mediático actual; y a través de las reseñas de Romero nos vinculamos a una especial perspectiva respecto de la lectura proporcionada por Michèle Petit, quien articula una perspectiva psicoanalítica con un abordaje socioantropológico. Amavet nos acerca al texto de Serres, quien realiza una mirada atenta a los cambios sociales y culturales de Occidente para poder pensar y proyectar la inserción de los jóvenes en el marco de rotundas transformaciones.

De esta manera, desde un puñado de artículos se abren preguntas, experiencias, direcciones para continuar pensando acerca de los nuevos sentidos de la alfabetización.

Victoria Baraldi 